\title{
Chondromesenchymal hamartomas in a 24- year-old male mimicking a posterior mediastinal tumor and a 5-month-old boy with postoperative disseminated intravascular coagulation: two case reports
}

Yue Li ${ }^{1,2}$, Danyang Zheng ${ }^{1,3}$, Min Zuo ${ }^{4}$, Yang $\mathrm{Li}^{5,6^{*}}$ and Huizhong Zhang ${ }^{1,3^{*}}$

\begin{abstract}
Background: Chondromesenchymal hamartoma of the chest wall is a rare, benign disease that usually presents at birth or in early infancy. It typically involves one or more ribs, forming a unilateral or bilateral extrapleural mass. Patients may be asymptomatic or complain of mild respiratory distress depending on tumor size and location. To the best of our knowledge, only two of the approximately 100 cases reported so far are adults.

Case presentation: We present two cases of chondromesenchymal hamartoma. The first case involved the left fifth rib in a 24-year-old male, in close proximity to the fifth vertebral body in the left posterior mediastinum, mimicking a posterior mediastinal tumor on imaging. The tumor was excised via thoracoscopy and the patient had an uneventful postoperative course. The second case was that of a 5-month-old boy, who had a tumor involving the left fifth and sixth ribs which caused thoracic cage collapse. Following en bloc resection of the tumor and the involved rib segments, the patient was transferred to the intensive care unit for treatment of pulmonary infection and disseminated intravascular coagulation (DIC). He was discharged from the hospital in stable condition 11 days later. On histopathology, the tumor was found to be a chondromesenchymal hamartoma with immature spindle-shaped mesenchymal cells, plate-like hyaline cartilage, areas of woven bone formation, endochondral ossification and calcification, osteoclastic giant cells, and secondary aneurysmal bone cysts.

(Continued on next page)
\end{abstract}

\footnotetext{
*Correspondence: li_yang_yang99@aliyun.com; zhanghuizh@sysucc.org.cn

${ }^{5}$ Department of Pathology, The First Affiliated Hospital, Sun Yat-sen

University, No. 58, Zhongshan Road II, Guangzhou 510080, China

'State Key Laboratory of Oncology in South China, Collaborative Innovation

Center for Cancer Medicine, Sun Yat-sen University Cancer Center, Guangzhou 510060, China

Full list of author information is available at the end of the article
}

(c) The Author(s). 2020 Open Access This article is licensed under a Creative Commons Attribution 4.0 International License, which permits use, sharing, adaptation, distribution and reproduction in any medium or format, as long as you give appropriate credit to the original author(s) and the source, provide a link to the Creative Commons licence, and indicate if changes were made. The images or other third party material in this article are included in the article's Creative Commons licence, unless indicated otherwise in a credit line to the material. If material is not included in the article's Creative Commons licence and your intended use is not permitted by statutory regulation or exceeds the permitted use, you will need to obtain permission directly from the copyright holder. To view a copy of this licence, visit http://creativecommons.org/licenses/by/4.0/. The Creative Commons Public Domain Dedication waiver (http://creativecommons.org/publicdomain/zero/1.0/) applies to the data made available in this article, unless otherwise stated in a credit line to the data. 


\begin{abstract}
(Continued from previous page)
Conclusions: Although the presently reported cases have morphological characteristics similar to previously reported ones, they had distinct radiological and clinical characteristics. Patient 1 is only the third report of an adult with chondromesenchymal hamartoma. His case was characterized by its radiological appearance mimicking a posterior mediastinal tumor. Patient 2 represents the first documentation of DIC as a postoperative complication following excision of a chondromesenchymal hamartoma. We present these two cases to provide clinicopathological insights regarding this extremely rare tumor that are relevant to both pathologists and clinicians.
\end{abstract}

Keywords: Chondromesenchymal hamartoma, Ribs, Adult, Infant, Pathological diagnosis

\section{Background}

Chondromesenchymal hamartoma of the chest wall presents at birth or in early infancy as an intraosseous expansile mass involving the ribs. It has an incidence of about $0.03 \%$ among primary bone tumors and shows male predominance; approximately 100 cases have been reported worldwide [1]. The tumor is composed of a disorganized admixture of cartilaginous components, spindle cell fascicles, woven bone, and hemorrhagic cysts. Surgical resection is the appropriate treatment and careful follow-up is necessary for early recognition of complications. In some cases, the aggressive appearance of the tumor may prompt unnecessary extended surgery with chest wall reconstruction, which may lead to complications such as trunk deformity and scoliosis [2]. There is no specific immunohistochemical (IHC) marker for this unusual disease. Histologic examination is generally adequate to establish the diagnosis, given the unique morphologic features. Imaging studies offer important clues; however, image-based diagnosis may be difficult, especially with atypical patient age or tumor location. The present case reports illustrate the need for a high suspicion index for chondromesenchymal hamartoma in similar cases.

\section{Case presentations}

Case 1: Chondromesenchymal hamartoma in a 24-yearold male mimicking a posterior mediastinal tumor

A chondromesenchymal hamartoma of the chest wall was incidentally discovered on the imaging studies of a 24-yearold male who presented with complaints of persistent cough in May 2019. Digital radiography (DR) was suggestive of a left posterosuperior mediastinal mass with bronchial changes (Fig. 1a-b). Computerized tomography (CT) revealed a benign expansile lesion in the posterior part of the left fifth rib with interior punctate calcifications, suggestive of an enchondroma (Fig. 1c). Magnetic resonance imaging (MRI) revealed a well-defined dumbbell shaped lesion with equal T1 and long T2 signals. The lesion measured approximately 32 $\mathrm{mm} \times 25 \mathrm{~mm}$. The expansile heterogeneous soft tissue lesion arising from the left fifth rib closely adjoined the fifth vertebral body in the left posterior mediastinum. The mass was characterized by substantially restricted diffusion and progressive heterogeneous enhancement (Fig. 1d-f). We suspected a chondrogenic or a neurogenic tumor of the left posterior mediastinum. Following preoperative optimization, the mass was thoracoscopically excised; intercostal nerve block and T4-6 pedicle internal fixation were performed. The patient had an uneventful recovery and was discharged in stable condition on the third postoperative day.

\section{Case 2: Chondromesenchymal hamartoma in a 5-month- old boy with postoperative disseminated intravascular coagulation}

A 5-month-old boy was admitted to the hospital with an asymptomatic, progressively enlarging painless mass in the left infra-axillary area of the lateral chest wall in August 2015. DR revealed a well-circumscribed soft tissue mass in the left middle lung field, measuring approximately $47 \mathrm{~mm} \times 39 \mathrm{~mm}$, accompanied by collapse of the adjacent thoracic cage and deformation of the left fifth and sixth ribs. The lesion was suspected to be a benign chondrogenic tumor (Fig. 2a-b). CT revealed a benign tumor or tumor-like lesion involving the axillary segments of the left fifth and sixth ribs (Fig. 2c). The corresponding cortical and medullary rib cavities were involved and the mass was solid-cystic with several speckled and cord-like high-density internal shadows (Fig. 2d). There was mild enhancement in the solid areas and lack of enhancement in the cystic areas. Localized emphysema in the left lung field was also observed. Based on these radiographic characteristics and the patient's age, a preoperative diagnosis of mesenchymal hamartoma was made. Two weeks later, the infant underwent en bloc resection of the tumor and the involved rib segments. The marrow cavity was sealed using bone wax and a thoracic tube drain was placed.

Postoperatively, the infant developed fever (maximum temperature, $39.7^{\circ} \mathrm{C}$ ) with marked elevation of $\mathrm{C}$-reactive protein and procalcitonin levels and white blood cell count. He was transferred to the intensive care unit and started on vancomycin and ceftazidime for a presumptive diagnosis of pulmonary infection. Coagulation function tests were suggestive of disseminated intravascular coagulation (DIC): D-dimer, $5.36 \mathrm{mg} / \mathrm{L}$; antithrombin III, 67.4\%; 

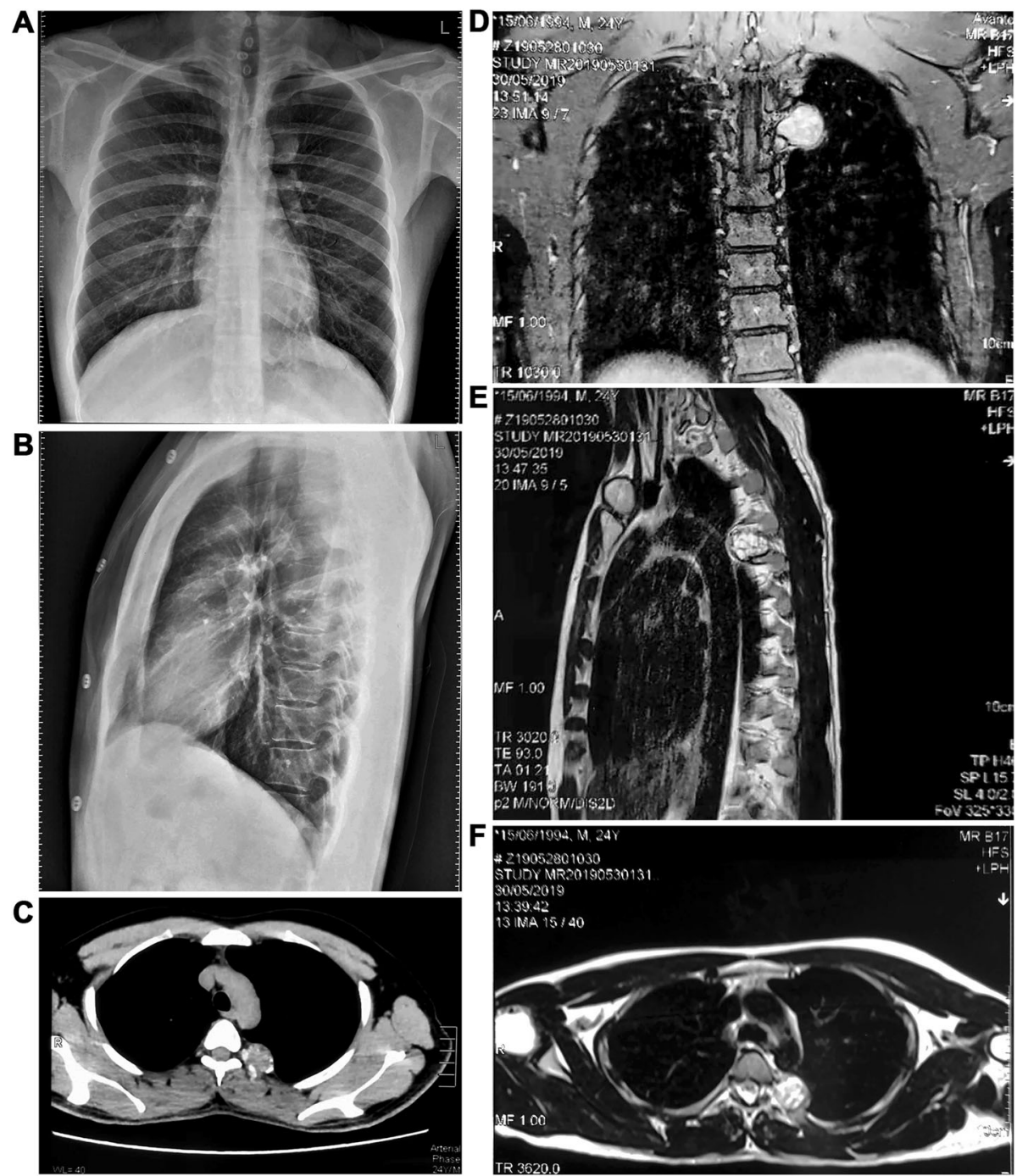

Fig. 1 Radiological appearance of chondromesenchymal hamartoma of the chest wall in a 24-year-old adult. a, b DR suggested a left posterosuperior mediastinal mass and bronchitic changes. $\mathbf{c} \subset$ revealed a benign expansile lesion in the posterior part of the left fifth rib with interior punctate calcifications. d-f MRI revealed a well-circumscribed expansile heterogeneous soft mass closely adjoining the fifth vertebral body in the left posterior mediastinum. DR, digital radiography; $C$, computed tomography; $D R$, digital radiography; $M R l$, magnetic resonance imaging

fibrinogen degradation products, $11.3 \mu \mathrm{g} / \mathrm{mL}$; prothrombin time, $19.4 \mathrm{~s}(11.0-4.0 \mathrm{~s})$; activated partial thromboplastin time, $62.6 \mathrm{~s}(25.0-35.0 \mathrm{~s})$; and fibrinogen, $5.38 \mathrm{~g} / \mathrm{L}$ $(2.00-4.00 \mathrm{~g} / \mathrm{L})$. Heparin sodium was administered as an anticoagulant and fresh frozen plasma was transfused to correct coagulation disorders. Subsequently, the infant's condition improved, the thoracic tube drain was removed 7 days after surgery, and the infant was discharged from the hospital on the 11th postoperative day.

\section{Pathological findings}

Case 1

Macroscopically, the tumor was multilocular and measured approximately $3.5 \mathrm{~cm} \times 2.5 \mathrm{~cm} \times 1.5 \mathrm{~cm}$. Microscopically, the solid area consisted of hyaline cartilage with endochondral calcification (Fig. 3a-b) and ossification and fascicles of mesenchymal spindle-shaped cells (Fig. 3c-f). The cystic portion was composed of aneurysmal bone cyst (ABC)-like structures (i.e. hemorrhagic spaces enclosed by fibrous connective cyst walls with scattered osteoid trabeculae and osteoclastlike giant cells). Moreover, ossification could be frequently observed within the fibrous walls and in the cartilage background (Fig. 3g-h). As the name "chondromesenchymal hamartoma" implies, there are typically several different histological components mixed together in a non-malignant pattern: mesenchymal spindle cells, frequent ossification, and secondary changes such as multinucleated osteoclastic giant cells and hemorrhagic spaces with fibrous cystic walls (Fig. $3 \mathrm{i}-\mathrm{j}$ ). 

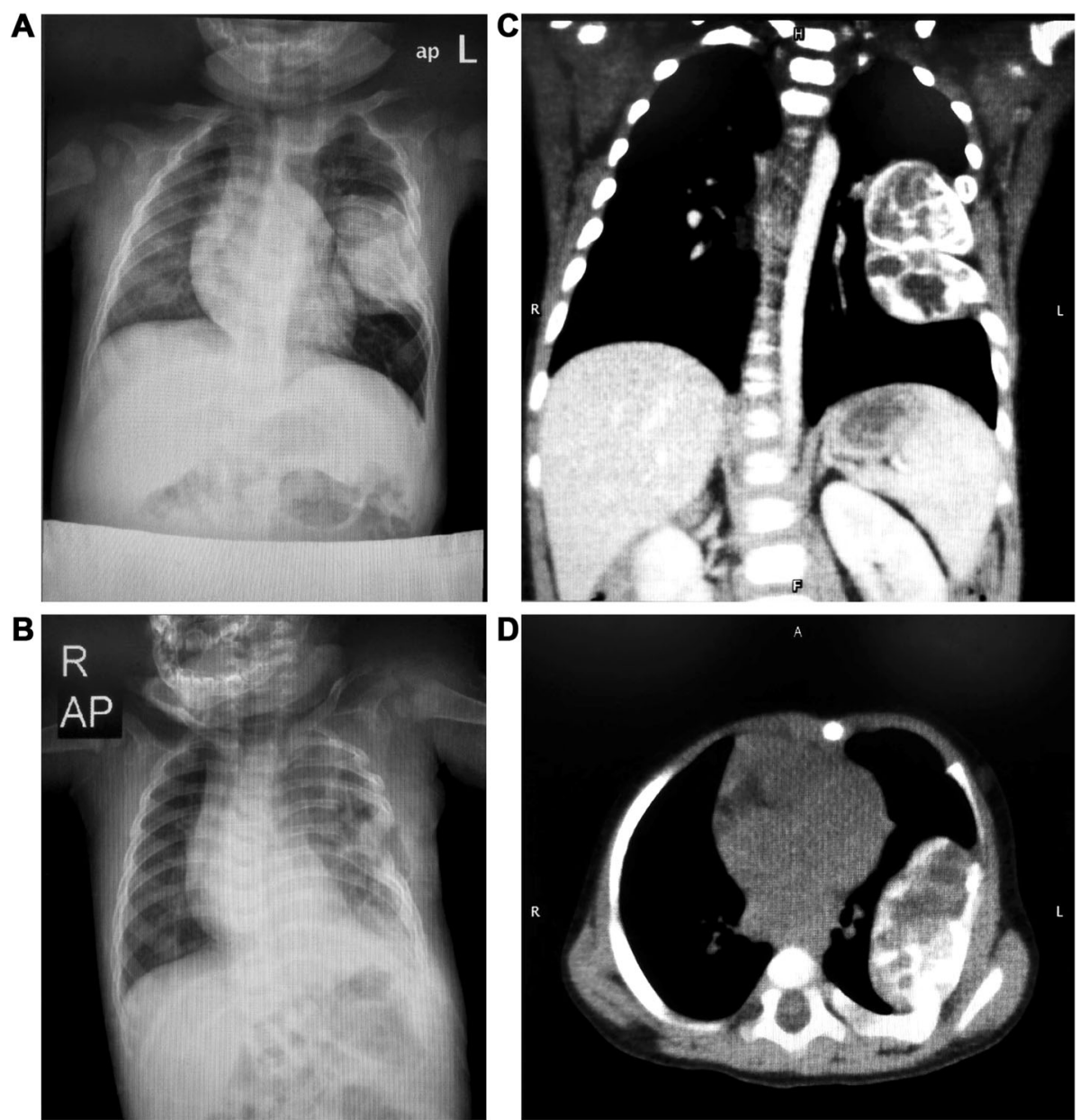

Fig. 2 Imaging findings of chondromesenchymal hamartoma of the chest wall in a 5-month-old infant. a DR revealed a soft tissue mass in the left middle lung field, accompanied by collapse of the adjacent thoracic cage. $\mathbf{b}$ DR revealed postoperative loss of parts of the left fifth and sixth ribs. $\mathbf{c}, \mathbf{d}$ CT revealed a benign solid-cystic lesion with multiple speckled and cord-like high-density shadows, arising from the axillary segment of the left fifth and sixth ribs; the corresponding cortical and medullary cavities of the ribs were involved. DR, digital radiography; $C$, computed tomography

In addition, fluorescence in situ hybridization (FISH) detection using USP6 break-apart probes was conducted for case 1. The USP6 break-apart FISH result was negative (Fig. 4a-b), which strongly rules out primary $A B C$.

\section{Case 2}

The tumor measured approximately $5 \mathrm{~cm}$ in diameter with focal cystic changes. Microscopically, most of the solid section's area consisted of fascicles of mesenchymal spindle cells interwoven with multilobulated hypercellular hyaline cartilage (Fig. 5a-b). Scattered woven bones and osteoclastic giant cells were mixed with spindle cells and surrounded by cartilage (Fig. $5 \mathrm{c}$-d). Some myeloid tissues could be observed among the lobulated cartilage (Fig. 5e$\mathrm{f})$, which confirmed the CT findings of tumor involvement of the corresponding cortical and medullary rib cavities. The cystic area comprised various-sized blood-filled spaces enclosed mostly by fibrous connective tissue, identified as secondary ABCs (Fig. 5g-h). Similarly to case 1 , ossification could also be found in the form of spindleshaped fibroblasts and cartilage in this case.

Collectively, the histological features of both cases were consistent with the diagnosis of chondromesenchymal hamartoma of the chest wall.

\section{Follow-up information}

The 24-year-old male (case 1) had DR examinations at 1 month and 3 months postoperatively, which showed no sign of recurrence, T4-6 pedicle internal fixation could still be observed and the remnant lung had a normal appearance. For case 2, the patient had DR examinations every year since the surgery in 2015 , which showed no sign of recurrence and a normal lung appearance. Both patients had neither respiratory issues nor any other newly discovered tumor at the last follow-up on January 30th, 2020. 


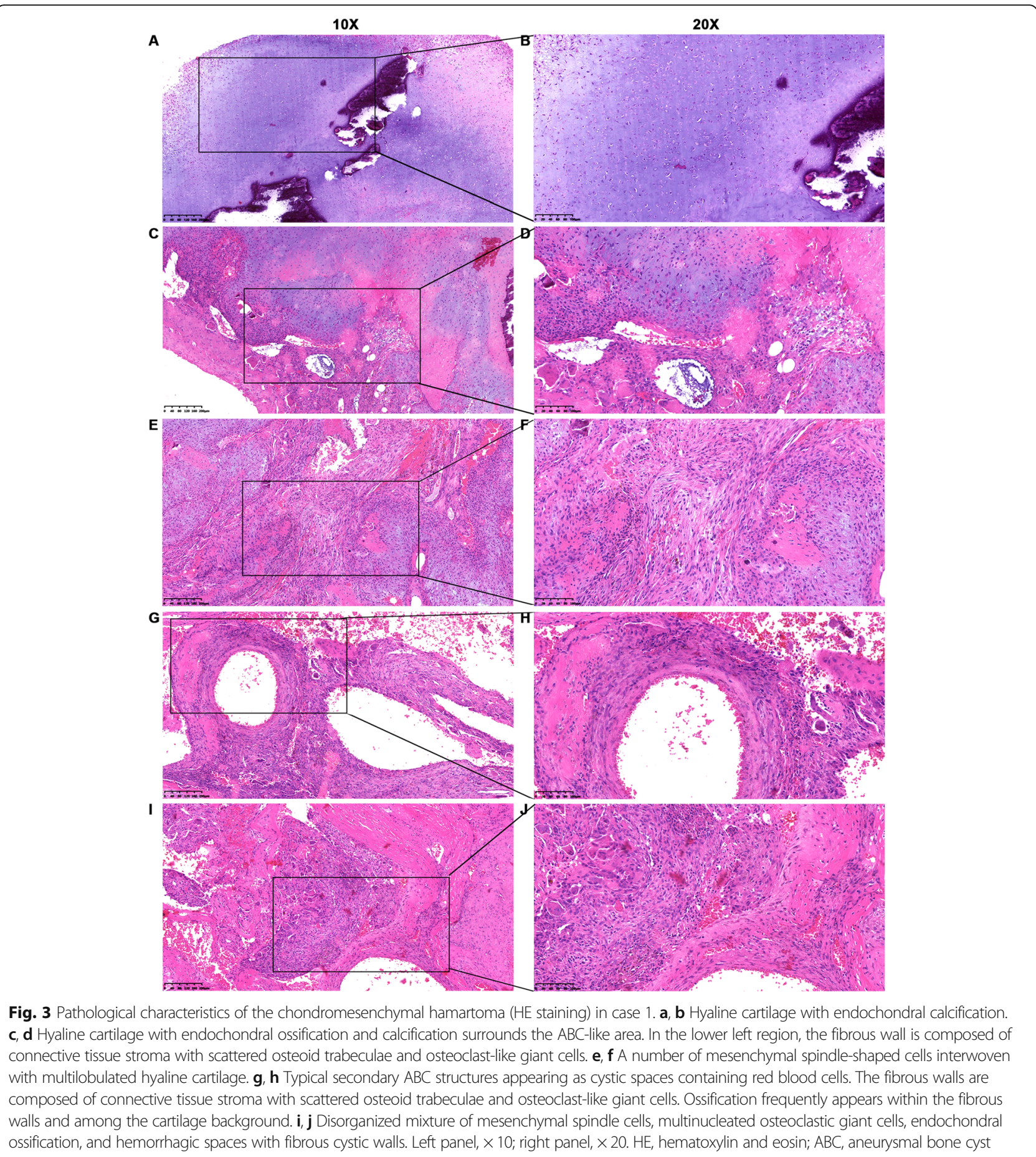

\section{Discussion and conclusions}

The term "mesenchymal hamartoma" was first proposed in 1979 by McLeod and Dahlin, as it best reflected the benign nature of this lesion composed of disordered but non-neoplastic skeletal tissues [3]. Odell and Benjamin were the first to use the term "mesenchymal hamartoma of the chest wall" in 1986 [4]. Its incidence is estimated to be 1 in 3000 among primary bone tumors or less than
1 per million in the general population [5]. Approximately 100 cases have been described to date, most occurring prenatally or within the first 6 months of life [6]. To the best of our knowledge, only two cases of chondromesenchymal hamartoma have been reported in adults. Bilateral multifocal lesions (CT revealed three masses on the right side and two masses on the left side) were discovered in a 47-year-old man who did not 


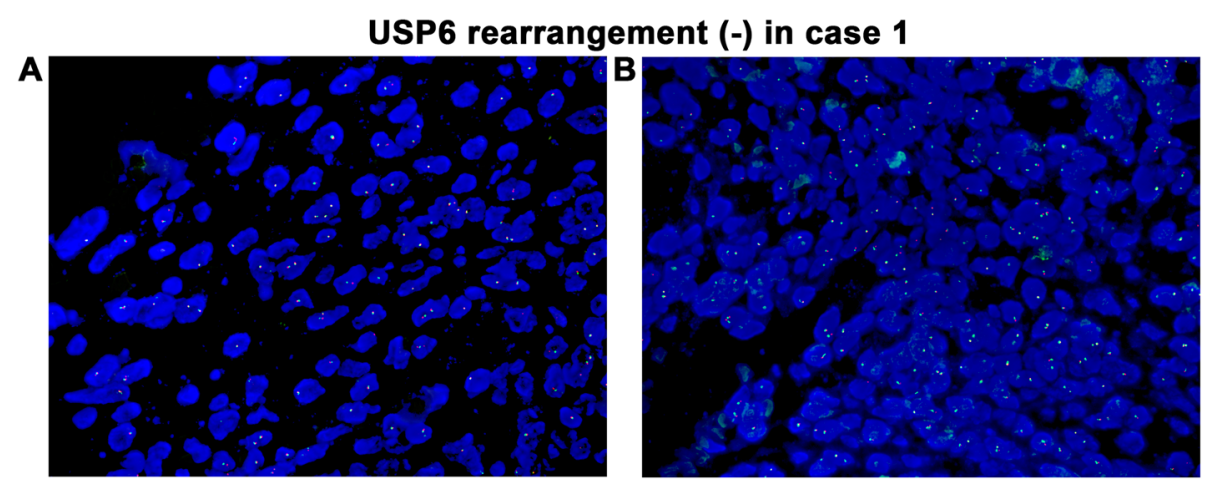

Fig. 4 USP6 rearrangement detection by a break-apart probe was negative in case 1. a, b Two different fields showing how the red and green signals did not break apart but rather appear in the same position or in close positions within the nuclei of the spindle-cell population, which should be interpreted as negative according to the manufacturer's criteria $(\times 100)$

undergo treatment until 13 years later when he developed chest pain [7]. Another asymptomatic left chest wall tumor was discovered incidentally during a complete medical checkup in a 39-year-old woman. The tumor was excised en bloc with segments of the 7th and 8th ribs [8]. The age of onset in our case ( 24 years old) is also quite uncommon, making this only the third adult patient with chondromesenchymal hamartoma reported worldwide.

Chondromesenchymal hamartomas are usually unilateral and are commonly seen on the right side, with a male-to-female ratio of 1.6:1 [9]. A few cases of bilateral lesions have also been reported [1, 7, 10]. Typically, these lesions arise from one or several ribs and their size may range from a few to a dozen centimeters. In most cases, these lesions occur in isolation; however, they are occasionally multifocal $[7,11,12]$. Patients may present with respiratory distress or be asymptomatic. Less common manifestations include scoliosis, chest wall deformity, cough, and fever [1]. One infant died 14 days after birth of severe sepsis secondary to Pseudomonas aeruginosa infection and pulmonary insufficiency [13]. Patient 2 in this report is the first documented instance of DIC as a postoperative complication following excision of chondromesenchymal hamartoma. Although this complication may not be directly related to this condition or its surgical treatment, it remains a possibility; therefore, we believe that assessing coagulation function preoperatively is important.

Imaging studies are helpful in determining the site of origin, tumor density, enlargement, and effect on adjacent structures; however, imaging is not considered diagnostic and may be misleading if the tumor location or patient age is atypical $[14,15]$. In patient 1 , the imaging finding of a paravertebral mass in an adult appeared to mimic a posterior mediastinal tumor and the radiologist suggested the possibility of a neurogenic tumor. Malignant lesions such as congenital neuroblastoma, Ewing's sarcoma, malignant teratoma, osteosarcoma, or chondrosarcoma cannot be excluded in the presence of cortical erosion, rib destruction, or deformation of adjacent ribs as seen on imaging $[16,17]$. Biopsy of the lesion can be complicated by severe bleeding because of disruption of the vascular spaces; therefore, needle biopsy should be performed cautiously $[1,2]$.

Microscopically, chondromesenchymal hamartomas have immature spindle-shaped mesenchymal cells, platelike hyaline cartilage, woven bone formation, endochondral ossification and calcification, osteoclastic giant cells, and secondary $\mathrm{ABC}$ changes; abnormal mitoses and atypia are not present [18]. Woven trabeculae containing hematopoietic marrow are common, as observed in patient 2. Areas resembling $\mathrm{ABC}$, with osteoclast-like giant cells, blood-filled spaces, hemosiderin-laden macrophages, and fibromembranous septa, are specific for chondromesenchymal hamartoma. It has been proposed that the formation of an $\mathrm{ABC}$ is secondary to intraosseous arteriovenous fistula formation [19]. IHC staining may demonstrate the presence of S-100 protein in cartilaginous areas [4]. To the best of our knowledge, no current molecular genetic tests are available to assist in the diagnosis of chondromesenchymal hamartoma [10].

The differential diagnosis of chondromesenchymal hamartoma includes tumoral and non-tumoral lesions involving the ribs that are common in infants and children, including primary $\mathrm{ABC}$, chondrosarcoma, enchondroma, osteochondroma, fibrous dysplasia, and osteofibrous dysplasia (OFD) [14]. Primary ABC and chondromesenchymal hamartoma both show cystic areas; however, they lack solid cartilage nodules and component diversity. It is noteworthy that $\mathrm{ABC}$ could be secondary to various bone tumors, including giant cell tumors, chondroblastomas, fibrous histiocytomas, chondromyxoid fibromas, fibrous dysplasia, and osteosarcoma [20]. Chondrosarcoma is primarily a tumor of adulthood and older age [21]. It is characterized by high cellularity, presence of host bone 


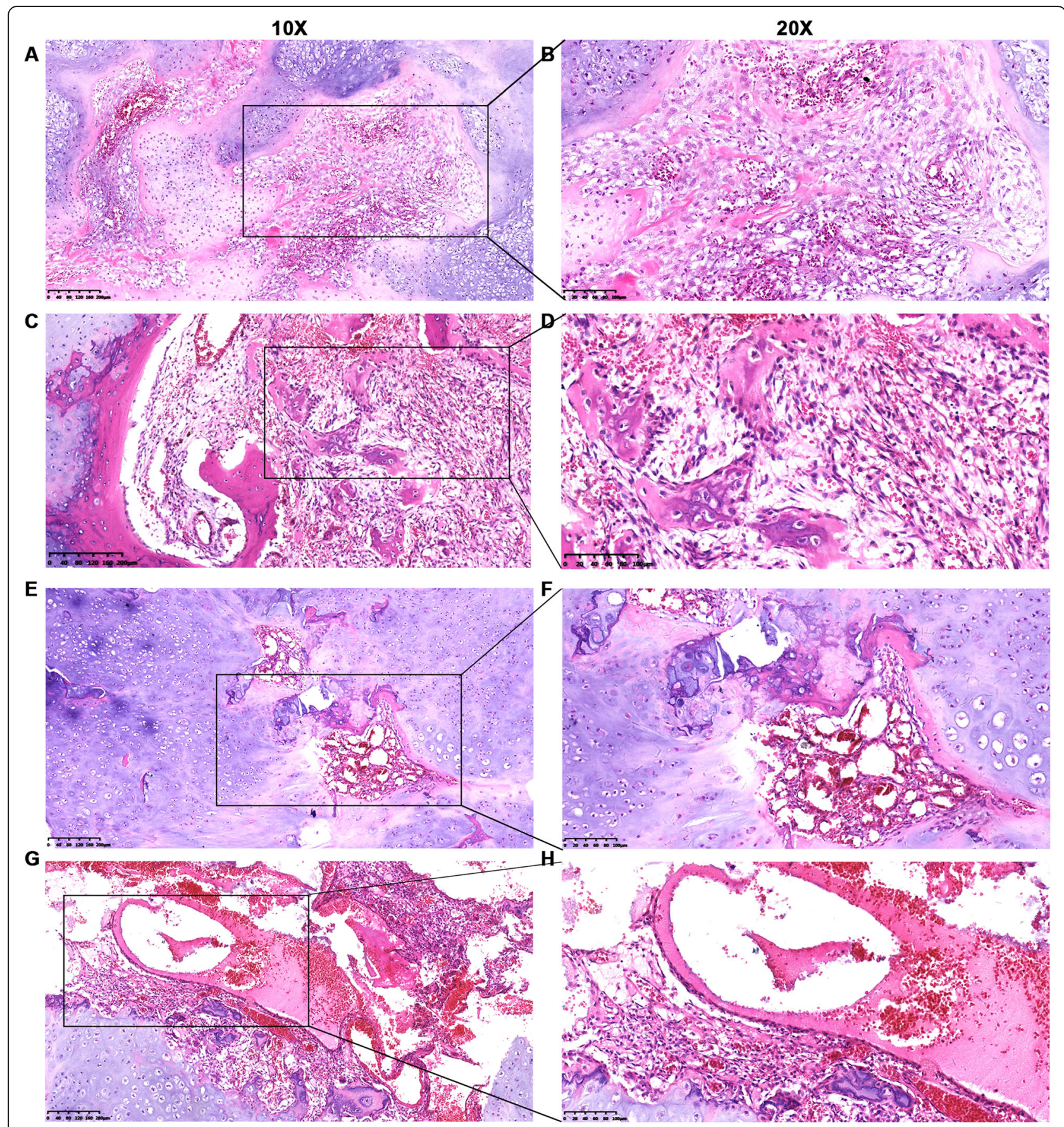

Fig. 5 Pathological features of chondromesenchymal hamartoma (HE staining) in case 2. a, b Fascicles of mesenchymal spindle cells interwoven with multilobulated hypercellular hyaline cartilage. $\mathbf{c}$, $\mathbf{d}$ Disorganized mixture of cartilage, spindle cells, osteoid trabeculae, and osteoclastic giant cells. e, f Focal myeloid tissues and osteoid trabeculae scattered among hypercellular plate-like cartilage. $\mathbf{g}, \mathbf{h}$ Fragmented cartilage mixed with osteoid trabeculae, osteoclast-like giant cells, and blood-filled spaces enclosed by fibrous connective cyst walls. Left panel, $\times 10$; right panel, $\times 20$. $\mathrm{HE}$, hematoxylin and eosin

entrapment, and absence of host bone encasement. Chondrosarcoma is characterized by mild-to-moderate atypical chondrocytes, varying in size and shape, and containing enlarged, hyperchromatic nuclei. Myxoid changes or chondroid matrix liquefaction is a common feature of chondrosarcomas [22]. Enchondroma is a benign hyaline cartilage neoplasm arising within the medullary bone cavity; normal bone marrow elements may also be observed between its nodules, as seen in patient 2. Noticeably, enchondroma often appears as pale blue on hematoxylin 
and eosin staining owing to its high matrix proteoglycan content and it is less diverse in terms of histological components than chondromesenchymal hamartoma. Osteochondroma originates from the bone surface and possesses a distinctive three-layer structure of perichondrium, cartilage, and bone. The outer layer is a fibrous perichondrium that is continuous with the periosteum, below which is a hyaline cartilage cap with endochondral ossification. Similar to chondromesenchymal hamartoma, fibrous dysplasia can occur in the ribs, contain a cartilaginous component with endochondral ossification, and have secondary changes including $\mathrm{ABC}$-like areas and multinucleated osteoclastic giant cells. However, fibrous dysplasia is mainly composed of bland fibroblastic cells and irregular trabeculae of woven bone; mesenchymal cells and plate-like hyaline cartilage are not its main components [22]. OFD mostly involves cortical bone of the anterior mid-shaft of the tibia during infancy and childhood; it is composed of fragments of woven bone rimmed by lamellar bone layers laid down by well-defined osteoblasts [22]. Although secondary ABC and multinucleated giant cells may be seen in OFD, there is an absence of cartilage. Lung hamartoma, which is the most common cartilage-containing benign lung tumor, should also be taken into consideration in the differential diagnosis. Since this tumor is composed of tissues that are normally present in the lung, the presence of normal bronchial epithelium could be a valuable clue [23]. Unlike chondromesenchymal hamartoma, lung hamartoma is mostly found in the lung parenchyma or within the bronchus and may only secondarily involve the ribs [24].

Molecular diagnostic techniques have recently emerged as independent diagnostic tools to improve diagnostic accuracy and reduce interobserver variability; many characteristic genetic alterations have been identified in bone tumors [25]. USP6 and/or CDH11 rearrangements are found in 69\% of primary $\mathrm{ABCs}$, but not in secondary $\mathrm{ABC}$ [26]. IDH1 (R132C; R132H) or IDH2 (R172S) mutations may occur in enchondromas, atypical cartilaginous tumor/grade 1 central chondrosarcomas, grade $2 / 3$ central chondrosarcomas, and dedifferentiated chondrosarcomas; however, they are absent in osteochondromas [27, 28]. MDM2 and CDK4 are amplified in low-grade central osteosarcomas and periosteal osteosarcomas, as demonstrated by FISH/IHC [29]. K36M mutations in $H 3 F 3 B$ appear in about $95 \%$ of chondroblastomas, while G34W/L mutations in $H 3 F 3 A$ are found in $92 \%$ of giant cell tumors of the bone [30]. It is likely that molecular markers will increasingly play an important role in improving the diagnosis and treatment of bone tumors.

The treatment strategy for chondromesenchymal hamartoma involves one of two main approaches: conservative management for asymptomatic patients and surgical treatment for patients with respiratory distress caused by mass compression. A case of spontaneous regression of a chest wall hamartoma in an infant was reported [31]. In most cases, surgical resection is chosen irrespective of symptoms. Secondary surgery may be required following incomplete resections [9]. Patients with significant upper airway obstruction may need permanent tracheotomy [32]. A third management option, radiofrequency thermoablation (RFT), a relatively noninvasive technique performed under CT guidance, was performed in a 6-monthold girl [33]. RFT causes coagulative necrosis in the lesion, which is gradually reabsorbed. This method avoids damage to the adjacent normal bone and is well tolerated in children, thereby decreasing the risk of severe postoperative complications [34].

Herein, we reported two extremely rare cases of chondromesenchymal hamartoma. Although the lesions in these cases were morphologically similar to previously reported cases, they had distinct radiological and clinical characteristics. To the best of our knowledge, case 1 is only the third report of an adult patient with chondromesenchymal hamartoma. This patient was suspected of having a posterior mediastinal tumor on radiology. Case 2 is the first documentation of DIC as a postoperative complication of chondromesenchymal hamartoma. This report may raise awareness regarding the presentation, diagnosis, and management of chondromesenchymal hamartoma among pathologists, radiologists, and clinicians.

\section{Abbreviations \\ ABC: Aneurysmal bone cyst; CT: Computerized tomography; DIC: Disseminated intravascular coagulation; DR: Digital radiography; FISH: Fluorescence in situ hybridization; IHC: Immunohistochemical; MRI: Magnetic resonance imaging; OFD: Osteofibrous dysplasia; RFT: Radiofrequency thermoablation}

\section{Acknowledgements} Not applicable.

\section{Authors' contributions}

Yue $L$ collected the patients' clinical history and drafted the manuscript. Yue $L$ and DZ performed the FISH experiment. MZ, YL and $H Z$ interpreted the histological examination. $Y L$ and $\mathrm{HZ}$ conceived the study and revised the manuscript. All authors read and approved the final manuscript.

\section{Funding}

None.

\section{Availability of data and materials}

The datasets used and/or analyzed during the current study are available from the corresponding author on reasonable request.

\section{Ethics approval and consent to participate}

Informed consent was obtained from the patient or legal guardian as applicable. The study was approved by the Ethics Committee of Sun Yat-sen University Cancer Center.

\section{Consent for publication}

Written informed consent was obtained from the patient or legal guardian for publication of this case report and any accompanying images. A copy of the written consent is available for review by the Editor-in-Chief of this journal.

Competing interests

The authors declare that they have no competing interests. 


\section{Author details}

'State Key Laboratory of Oncology in South China, Collaborative Innovation Center for Cancer Medicine, Sun Yat-sen University Cancer Center, Guangzhou 510060, China. '2Department of Molecular Diagnostics, Sun Yat-Sen University Cancer Center, Guangzhou 510060, China. ${ }^{3}$ Department of Pathology, Sun Yat-Sen University Cancer Center, Dongfeng Road, Yuexiu District, No. 651, Guangzhou 510060, China. ${ }^{4}$ Department of Pathology, First Affiliated Hospital of Southern University of Science and Technology, Second Clinical Medical College of Jinan University, Shenzhen People's Hospital, Shenzhen 518020, China. ${ }^{5}$ Department of Pathology, The First Affiliated Hospital, Sun Yat-sen University, No. 58, Zhongshan Road II, Guangzhou 510080, China. ${ }^{6}$ Department of Pathology, Guangzhou Concord Cancer Center, Guangzhou 510045, China.

Received: 6 August 2019 Accepted: 25 February 2020

Published online: 12 May 2020

\section{References}

1. Alfaraidi M, Alaradati H, Mamoun I, Mohammed S. Bilateral Mesenchymal Hamartoma of the Chest Wall in a 3-month-old boy: a case report and review of the literature. Case Rep Pathol. 2017;2017:2876342.

2. Jozaghi Y, Emil S, Albuquerque P, Klam S, Blumenkrantz M. Prenatal and postnatal features of mesenchymal hamartoma of the chest wall: case report and literature review. Pediatr Surg Int. 2013;29:735-40.

3. Richard DCD, McLeod A. Hamartoma (Mesenchymoma) of the Chest Wall in infancy. Radiology. 1979:131:657-61.

4. Odell JM, Benjamin DR. Mesenchymal hamartoma of chest wall in infancy: natural history of two cases. Pediatr Pathol. 1986;5:135-46.

5. Braatz B, Evans R, Kelman A, Cheng W. Perinatal evolution of mesenchymal hamartoma of the chest wall. J Pediatr Surg. 2010;45:e37-40.

6. Amstalden EM, Carvalho RB, Pacheco EM, Oliveira-Filho A, Stragea-Neto L, Rosenberg AE. Chondromatous hamartoma of the chest wall: description of 3 new cases and literature review. Int J Surg Pathol. 2006;14:119-26.

7. Altaner S, Sodhi KS, Menon P, Dey P, Khandelwal N. Multifocal mesenchymal hamartoma of the chest wall. Respirology. 2006;11:334-8.

8. Yamamoto H, Soh J, Ichimura K, Konishi Y, Toyooka S, Nojima T, Miyoshi S, et al. Adult mesenchymal hamartoma of the chest wall: report of a case. Ann Thorac Cardiovasc Surg. 2014;20:663-5.

9. Haase R, Merkel N, Milzsch M, Lieser U. Mesenchymal chest wall hamartoma—surgery is preferred. Arch Perinat Med. 2007;13:56-61.

10. Li R, Kelly D, Siegal GP. Bilateral mesenchymal hamartoma of the chest wall in an infant boy. Fetal Pediatr Pathol. 2012;31:415-22.

11. Troum S, Dalton ML, Donner RS, Besser AS. Multifocal mesenchymal hamartoma of the chest wall in infancy. J Pediatr Surg. 1996;31:713-5.

12. Sodhi KS, Aiyappan SK, Menon P, Dey P, Khandelwal N. Unilateral multifocal mesenchymal hamartoma of the chest wall: a case report and review of literature. J Pediatr Surg. 2009;44:464-7.

13. Serrano-Egea A, Santos-Briz A, Garcia-Munoz H, Martinez-Tello FJ. Chest wall hamartoma. Report of two cases with secondary aneurysmal bone cysts. Pathol Res Pract. 2001;197:835-9.

14. Yeshvanth SK, Shivamurthy V, Patil C, Rai S, Lakshminarayana KP, Makannavar $\mathrm{JH}$. Mesenchymal hamartoma of the chest wall- mimicker of malignancy. J Cancer Res Ther. 2011;7:496-8.

15. Kim JY, Jung WH, Yoon CS, Kim MJ, Kim HK, Kim KD, Cho SH, et al. Mesenchymal hamartomas of the chest wall in infancy: radiologic and pathologic correlation. Yonsei Med J. 2000;41:615-22.

16. Groom KR, Murphey MD, Howard LM, Lonergan GJ, Rosado-de-Christenson $\mathrm{ML}$, Torop AH. Mesenchymal hamartoma of the chest wall radiologic manifestations with emphasis on cross-sectional imaging and histopathologic comparison. Radiology. 2002;222:205-11.

17. Tanaka T, Fumino S, Shirai T, Konishi E, Tajiri T. Mesenchymal hamartoma of the chest wall in a 10-year-old girl mimicking malignancy: a case report. Skelet Radiol. 2019;48:643-7.

18. Patel RG, Dhotre SV, Goswami HM, Barot HP, Jadav MP. Review of mesenchymal hamartoma of chest wall in infancy-an unusual tumour. Int J Cur Res Rev. 2016:8:25-8.

19. Biesecker JL, Marcove RC, Huvos AG, Mike V. Aneurysmal bone cysts A clinicopathological study of 66 cases. Cancer. 1970:26:615-25.

20. Rădulescu R, Bădilă A, Manolescu R, Sajin M, Japie I. Aneurysmal bone cyst clinical and morphological aspects. Romanian J Morphol Embryol. 2014;55: 977-81.
21. Gambarotti M, Righi A, Picci P, Bertoni F, Manfrini M, Donati DM, et al. Paediatric chondrosarcomas: a retrospective review of 17 cases. Histopathology. 2016;68:1073-8.

22. CDM F, Bridge JA, Mertens F. WHO classification of tumors of soft tissue and bone, 4th ed. World Health Orgnization IARC. 2013. p. 185-6. https:// publications.iarc.fr/Book-And-Report-Series/Who-Classification-Of-Tumours/ WHO-Classification-Of-Tumours-Of-Soft-Tissue-And-Bone-2013.

23. Radosavljevic V, Gardijan V, Brajkovic M, Andric Z. Lung Hamartoma diagnosis and treatment. Med Arch. 2012;66:281-2.

24. Geramizadeh B, Mottavvas M, Zeyaian B, Amirian A. Giant hamartoma of lung presented with massive hemoptysis: a rare case report and review of the literature. Rare Tumors. 2019;11:1-4

25. Szurian K, Kashofer K, Liegl-Atzwanger B. Role of next-generation sequencing as a diagnostic tool for the evaluation of bone and soft-tissue tumors. Pathobiology. 2017:84:323-38.

26. Oliveira AM, Perez-Atayde AR, Inwards CY, Medeiros F, Derr V, Hsi BL, Gebhardt MC, Rosenberg AE, Fletcher JA. USP6 and CDH11 oncogenes identify the neoplastic cell in primary aneurysmal bone cysts and are absent in so-called secondary aneurysmal bone cysts. Am J Pathol. 2004;165:1773-80.

27. de Andrea CE, San-Julian M, Bovee J. Integrating morphology and genetics in the diagnosis of cartilage tumors. Surg Pathol Clin. 2017;10:537-52.

28. Amary MF, Bacsi K, Maggiani F, Damato S, Halai D, Berisha F, et al. IDH1 and $\mathrm{IDH} 2$ mutations are frequent events in central chondrosarcoma and central and periosteal chondromas but not in other mesenchymal tumours. J Pathol. 2011;224:334-43.

29. Righi A, Gambarotti M, Benini S, Gamberi G, Cocchi S, Picci P, et al. MDM2 and CDK4 expression in periosteal osteosarcoma. Hum Pathol. 2015;46:549-53.

30. Behjati S, Tarpey PS, Presneau N, Scheipl S, Pillay N, Van Loo P, et al. Distinct $\mathrm{H} 3 \mathrm{~F} 3 \mathrm{~A}$ and $\mathrm{H} 3 \mathrm{~F} 3 \mathrm{~B}$ driver mutations define chondroblastoma and giant cell tumor of bone. Nat Genet. 2013;45:1479-82.

31. Freeburn AM, McAloon J. Infantile chest hamartoma--case outcome aged 11. Arch Dis Child. 2001;85:244-5.

32. Cameron D, Ong TH, Borzi P. Conservative management of mesenchymal hamartomas of the chest wall. J Pediatr Surg. 2001;36:1346-9.

33. Bertocchini A, Falappa P, Accinni A, Devito R, Inserra A. Radiofrequency thermoablation in chest wall mesenchymal hamartoma of an infant. Ann Thorac Surg. 2007:84:2091-3.

34. Falappa P, Natali GL, Bertocchini A, Inserra A, Devito R. Minimal invasive technique in mesenchymal hamartoma of the chest wall: use of radiofrequency thermoablation. J Pediatr Surg. 2010;45:1072-3 author reply 1074

\section{Publisher's Note}

Springer Nature remains neutral with regard to jurisdictional claims in published maps and institutional affiliations.

Ready to submit your research? Choose BMC and benefit from:

- fast, convenient online submission

- thorough peer review by experienced researchers in your field

- rapid publication on acceptance

- support for research data, including large and complex data types

- gold Open Access which fosters wider collaboration and increased citations

- maximum visibility for your research: over $100 \mathrm{M}$ website views per year

At BMC, research is always in progress.

Learn more biomedcentral.com/submissions 